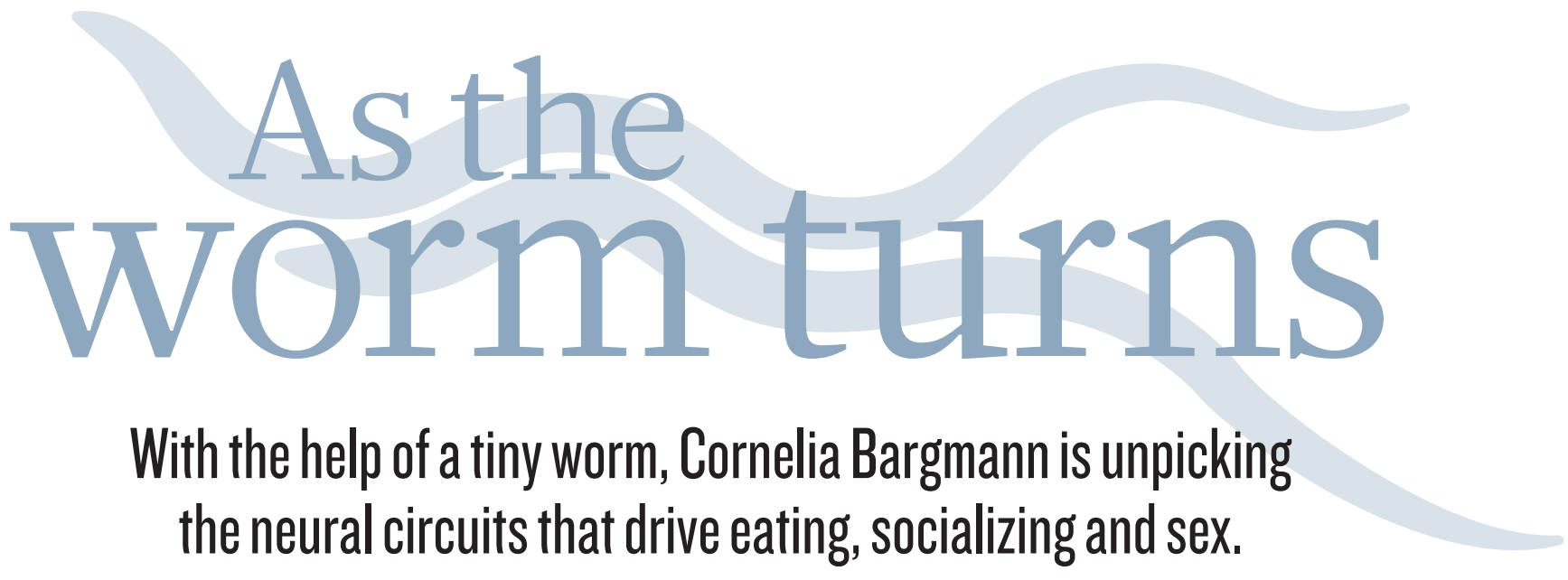

BY STEPHEN S. HALL

M ale sexual dysfunction is never pretty, even in nematodes. In normal roundworm courtship, a slender male will sidle up to a plump hermaphrodite, make contact, and then initiate a set of steps leading up to insemination: a sinuous backwards motion as he searches for the sexual cleft, a pause to probe, and finally the transfer of sperm. The whole business is usually over in a couple of minutes. "It's very slithery, and affectionate," says Cornelia Bargmann, who has been observing the behaviour of this particular worm, Caenorhabditis elegans, for 25 years.

Last October, scientists in Bargmann's laboratory at the Rockefeller University, New York, reported the discovery of a gene that seems to be crucial to successful mating. Disrupting the action of this gene causes male sexual confusion of almost epic pathos: nematodes with certain mutations poke tentatively at an inert hermaphrodite, making confused, fruitless curlicues around the potential mate. Occasionally the mutant male succeeds, but often he literally falls off the job and begins the search anew for a mate. Jennifer Garrison, a postdoc of Bargmann's who tracked the behaviour of these males, just shakes her head as she replays the scene on her computer screen. "Really sad," she says.

There are two punchlines to this story of thwarted invertebrate mating. One is the charming squeamishness with which Bargmann describes it, hesitating at words such as "vulva" and "spicule" and other anatomical gewgaws of roundworm reproduction. "As a well-brought-up Southern girl," she says with a laugh, "it's still difficult to talk about this!"

The other is scientific, supporting Bargmann's long-standing conviction that studying these deaf, part-blind, transparent creatures, which resemble nothing so much as wriggling specks of lint, could nonetheless yield enormous insight into how a nervous system creates behaviour. Since the 1980s, Bargmann and her colleagues have systematically explained the means by which worms taste and smell, exhibit social behaviours such as feeding in groups and explore their surroundings. She and her colleagues have parsed these behaviours down to the genes and circuitry of the neural connections that drive them. Just as studies of the fruitfly laid bare the basic principles of development and studies of yeast revealed the rules of the cell cycle, Bargmann believes that the simple nematode is revealing basic secrets about how animal nervous systems - including those of humans - translate sensory information into fundamental behaviours. "What are the most basic behaviours that every animal has to show and every animal has to solve?" she asks. "You can basically say that the three would be hunger, fear and reproduction. None of those things got invented last Saturday night!"

The evolutionary strength of that argument grew last year, when Bargmann and her colleagues published the experiments with the mutant males ${ }^{1}$. The mutation, they reported, is in a roundworm gene that they dubbed nematocin, which codes for a small peptide that influences multiple neurons and is a biochemical cousin to oxytocin and vasopressin, two hormones that play key parts in mammalian reproductive behaviour. Put another, Darwinian, way, the sexual confusion in mutant nematode males is tied to a molecule that seems to have been conserved in the nervous systems of animals at least since worms separated from vertebrates an estimated 600 million years ago. "Oxytocin and vasopressin are kind of at the top of the hierarchy of human neuropeptides in the brain," says biologist Scott Emmons of Albert Einstein College of Medicine in New York. "And you look in the worm and, lo and behold, you see the same thing, which is quite striking."

Although there had been some initial experimental forays into the behaviour of worms, says Paul Sternberg, who studies the nematodes at the California Institute of Technology in Pasadena, Bargmann took a more systematic, rational approach to dissecting its circuitry. "She made a major impact by taking that risk, and going broad and deep. She committed her life to this, and it's worked out beautifully."

\section{SPEAKING THE LANGUAGE}

Bargmann, now 51, grew up in Athens, Georgia, but steeped in European culture. Both her parents were born in Germany. Her father spoke to her in English; her mother in German. "Apparently, until I was 4 or 5 years old, I didn't realize that each of us spoke a different language when we were talking to each other," she says. Her fluency threw open a world of German-language books, including semi-popular accounts of animal behaviour written by Konrad Lorenz ${ }^{2}$ and Karl von Frisch ${ }^{3}$. "My mother had these books," Bargmann recalls. Decades later, some $\rightarrow$ NATURE.COM To watch worm mating in action, see: go.nature.com/rkvrtv of these pioneering ethology works are almost compulsory reading in the Bargmann lab.

Bargmann says that her true interest in science, however, dates back to an adolescent prank in school. "We were taking this Earth-science class, 


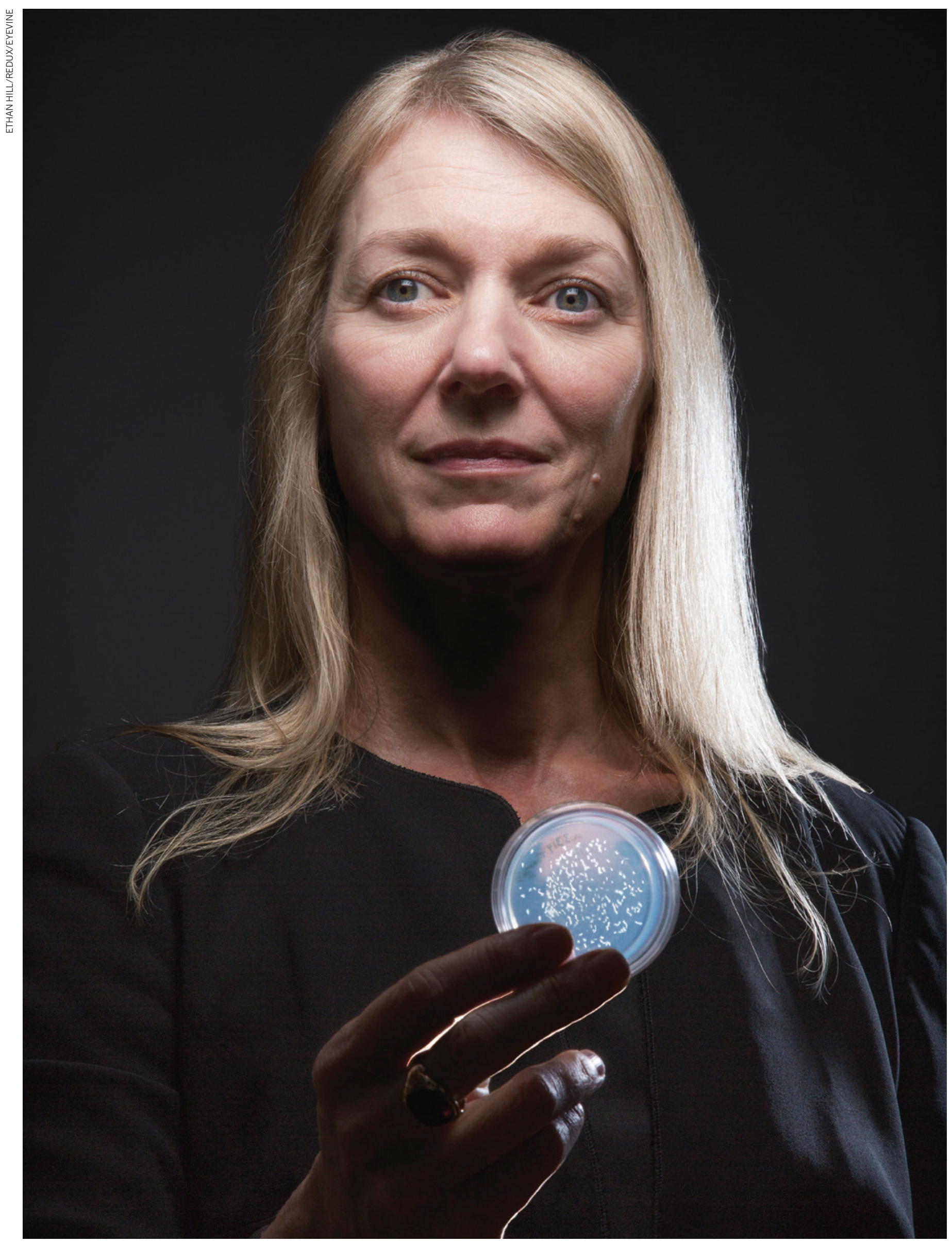


and the teacher told us that sodium was a metal and that if you placed it in water, it would burn," she says. "We were just electrified." With several classmates, Bargmann conspired to steal all the sodium from the school lab and test the hypothesis. "The sodium was flushed down the [boys'] toilet, which was blown off the wall!"

"This was literally the first time that science really struck me as something fun and exciting," Bargmann recalls. But she wasn't there to witness the explosion. "The ethics of the eighth grade is that you could be involved in stealing the sodium and you could be involved in planning the event," she says. "But there was no way that a girl was going to go into the boys' locker room." After a pause, she adds, with a smile, "It was a moment of weakness that I regret to this day."

Bargmann has put that regret to good use, crashing through one door after another ever since. She went on to become a biochemistry major (and class valedictorian) at the University of Georgia in Athens, before heading for graduate studies to the laboratory of Robert Weinberg, a molecular biologist at the Massachusetts Institute of Technology (MIT) in Cambridge. "Still waters run deep," says Weinberg, recalling the arrival of the soft-spoken Bargmann in 1981. "In the beginning, she didn't say much and was generally quiet, but I soon realized that she had a superior brain."

At the time, the Weinberg lab was using the newly minted tools of molecular biology to tease apart the mechanics of oncogenes - genes that, when mutated or hyperactive, trigger the unbridled cellular proliferation that drives cancer. Bargmann isolated and sequenced an oncogene called neu from a rat tumour ${ }^{4}$. Later, researchers would discover that some malignancies, notably breast cancer, express the same gene, known in humans as HER2. In the 1990s, the Californian biotechnology company Genentech in South San Francisco developed a drug to target breast cancers that overexpress this gene, and the resulting monoclonal antibody, trastuzumab (Herceptin) has since been used to treat nearly one million people with cancer. Bargmann says that she derives "immense personal satisfaction", but no significant royalties, from this early work.

Despite the heady start in a hot and highly visible field, Bargmann felt intimidated by the intellectual firepower of the people already in it. "It just wasn't so clear to me what I would do that was so different from what people like Weinberg and Harold Varmus were already doing," she says. So after receiving her PhD in 1987, she made a strategic - and quietly ambitious - decision to switch her area of research. Bargmann had always been fascinated by the neuroscience of behaviour, and the moment seemed right to bring molecular biology into the mix. After deciding against fruitflies (not enough neuroanatomy was known) and mice (the tools for genetic manipulation were still being developed), she settled on C. elegans.

The nematode had been earning a growing scientific constituency ${ }^{5}$ ever since the mid-1960s, when British biologist Sydney Brenner proposed it as a model system. The organism was sufficiently complex to share basic biological functions with more advanced organisms, but was also experimentally tractable, with just 959 cells in the hermaphrodite marbled along its 1-millimetre length. Work by Brenner and others has established that all of the nematode's fundamental behaviours - navigating, foraging and mating - are governed by a neural system that contains just 302 neurons in hermaphrodites and about 8,000 synaptic connections. (By contrast, the human nervous system has 80 billion to 100 billion neurons and perhaps 100 trillion synapses.) To Bargmann, the combination of a blueprint for an entire nervous system and the powerful new genetic techniques that she had just learned offered "alluring" possibilities to map molecules related to behaviour onto a wellestablished neuroanatomy. She opted to stay at MIT and do a postdoc in the laboratory of $\mathrm{H}$. Robert Horvitz, a leading C. elegans researcher.

Despite their relative simplicity, nematodes posed a daunting challenge to anyone interested in dissecting complex behaviours: it wasn't clear that they actually had any. Most behavioural studies in C. elegans had investigated very simple responses, or reflex actions. But Bargmann, reasoning that nematodes need a way to find food (usually bacteria grazing in foul-smelling, decomposing matter), decided to tackle their sensory behaviour: specifically, how they detect attractive or noxious chemicals around them, process that information and then use it to navigate towards or away from the source.

Bargmann first had to work through "some rather awful smelling substances", recalls Horvitz, to figure out which ones worms prefer. Then she used a technique called laser ablation to obliterate individual nerve cells. She identified a series of neurons that the soil-dwelling C. elegans uses to detect chemicals in its immediate environment ${ }^{6}$, and then went on to find neurons that responded to volatile odours - in effect demonstrating for the first time that nematodes had a sense of smell $^{7}$. Bargmann's systematic approach was "inspirational" to other worm biologists, Sternberg says.

Bargmann continued to explore worm olfaction after joining the faculty of the University of California, San Francisco, in 1991. In one study, her lab identified a receptor molecule, odr-10, in a pair of sensory neurons that detect diacetyl, an attractive odour associated with decaying food ${ }^{8}$. The lab correlated this and other mechanisms for sensing chemicals and heat with distinct nematode movements such as "pirouettes" and "omega turns", gradually assembling the neural circuitry of nematode navigation and exploration ${ }^{9}-$ a behaviour she sometimes calls, in casual conversation, "curiosity".

Soon, the lab began to uncover neural mechanisms that paralleled complex behaviour in other organisms. Bargmann knew that normal strains of roundworm vary in their feeding behaviour; some are solitary eaters, whereas others forage together in clumps of up to several hundred worms. Bargmann's lab showed that solitary eaters could be transformed into social eaters by inserting a slightly different version of the $n p r-1$ gene, which in worms encodes a receptor with biochemical cousins throughout the animal kingdom, known as neuropeptide $\mathrm{Y}$ receptor ${ }^{10}$. In other animals, neuropeptide $\mathrm{Y}$ regulates food consumption, mood and anxiety, among other things.

In a sense, the $n p r-1$ story primed Bargmann for the nematocin discovery more than a decade later, which ultimately brought her back to the German ethologists - and to a new hypothesis about the evolution of behaviour.

\section{DUE CREDIT}

Bargmann's eighth-floor office in a research tower at Rockefeller is a homespun museum to the breadth of her intellectual interests and the depth of her personal attachments. A framed, red, heart-shaped piece of art on one wall depicts the anatomical outline of a nematode superimposed on the wiring pattern of the mouse olfactory system - a wedding gift celebrating her 2007 marriage to neuroscientist Richard Axel, whose research on mammalian olfaction at Columbia University in New York won Nobel recognition in 2004. A row of 21 empty champagne bottles lines the window sill, each uncorked to celebrate the thesis defence of a graduate student. Bargmann's speech oscillates between quiet scientific precision and a generous compulsion to acknowledge the contributions of every student, colleague, mentor and scientific ancestor, so that her conversation sometimes seems like an extended, erudite, magnanimous footnote.

One such conversation leads to the tale of the sexually confused males. Molecules related to vasopressin and oxytocin had previously been identified in other branches of the animal kingdom that have very deep evolutionary roots, including octopuses and annelids, suggesting that the molecules had an ancient and conserved role in animal behaviour. Around 2004, Evan Macosko, a PhD student in Bargmann's 
lab, began scouring the C. elegans genome for the nematode version of oxytocin, but neuropeptides are very short and their genes are often hard to identify. He finally found a promising candidate in 2005, and the group went on to identify two nematocin receptors that were clearly related to the mammalian oxytocin receptor. Garrison's subsequent experiments with nematocin mutants dramatically confirmed that the peptide drives a basic behaviour ${ }^{1}$.

Other research groups had defined, in exquisite detail, the w series of discrete behavioural steps that male worms

have to complete to succeed in mating (search-

ing for a mate, contact, reverse turns, prod-

ding for the vulva, insertion of spicule,

transfer of sperm) as well as the motor

neurons and muscles that rapidly fire

and contract to drive these steps.

But when Bargmann and her team analysed how the absence of nematocin affected each of these steps, they realized that each one remained intact. "It's not that he can't turn. It's not that he can't do the backing movement. It's not that he can't transfer sperm. It's that he doesn't know when to do them," she says. The neuropeptide, in essence, had a "global organizing role" and gave reproductive behaviour a forward drive. “There's something that's a much slower input that says something more like 'continue' or 'move forwards', sort of providing momentum that's superimposed on it. So the nervous system is doing both fast and slow information processing, in parallel, to drive the behaviour."

This two-pronged neural processing reminded Bargmann of observations she had encountered decades earlier in the books in her mother's library. The pre-war ethologists - not only Lorenz and von Frisch, but also the Dutch scientist Niko Tinbergen - used astute field observations of fish, birds, insects and mammals to begin to assemble a fundamental grammar of behaviour. "[They] were the first to really express the idea that there were basic rules governing animal behaviours," she says, "and that you could recognize some of the same elements of those roles across very different animals."

A "fixed action response", for example, is a swift reaction to an environmental cue or threat. Tinbergen famously noted that the male stickleback fish in his lab aquaria flashed aggressive territorial behaviour when the local postal truck, painted red, rumbled by. He realized that the glimpse of red triggered a fixed, fast, hard-wired behavioural response because male sticklebacks display red bellies during mating season ${ }^{11}$. At the same time, the ethologists described an "innate releasing mechanism", a slower orchestration of these fast responses that increases the probability that a fundamental behaviour such as mating will occur.

Tinbergen and his peers "were trying to relate what they saw in different animals to a common logic", Bargmann says, and she believes that logic is at least partly explained by neuropeptides such as nematocin. According to this model, the ritual movements of mating are the fixed-action patterns and the neuropeptides are the innate releasing mechanism. “Those [peptides], in ways that at this point we're still trying to work out, change the properties of the neurons involved in those behaviours to help organize the outcome," she says.

Bargmann suspects that this broad picture of nervous-system organization sends a counter-intuitive message about the evolution of behaviour: that the sensory apparatus in each species is evolving rapidly and is highly divergent, creating a different set of behavioural cues and responses for different animals, whereas the overarching behavioural coordination exerted by neuropeptides remains largely evolutionarily conserved. "This is not the way we [usually] think of things in neuroscience," says Bargmann. "We always think the simplest part will be the sensory part, and maybe that will be the most conserved part. But in fact the sensory periphery is crazy unconserved between different animals." This picture assumes that nematocin and its cousins have similar roles across species, but some biologists are not yet convinced. "It is pleasing to find these evolutionary connections," says Sternberg,

"but we need more to know if the hypothesis is true."

The idea that peptides can have a global influence on what neurons in a network do is central to a debate roiling in the neuroscience community at the moment. A number of biologists are pushing to create the 'connectome' - a definitive wiring diagram that would map all the cells, synapses and neuromodulators in mammals and other complex organisms, and describe how those components interact to produce behaviour. It would be a massive, expensive undertaking.

Bargmann is all for connectivity maps, but she is not sure that, with current knowledge, they would explain as much as proponents hope. In an essay published last March" ${ }^{12}$, she warned that "it will not be possible to read a wiring diagram as if it were a set of instructions". Because neuropeptides can alter the excitability of neurons, the strength of synapses and even the overall function of a circuit, having a connectome is like having a street map without knowing how traffic flows through it, Bargmann says.

With nematocin in hand, the Bargmann lab is now trying to figure out what triggers its release, and how the peptide changes the activity of the neurons it targets. The team is also using nematocin to try to understand how social behaviours can differ within and between species. "Mating behaviours change rapidly over evolution compared to other behaviours," Bargmann notes. "How does that happen at a mechanistic level?"

Understanding the mechanics of the roundworm's simple nervous system, says Bargmann, "may be the only chance we have of figuring out a more complex system. I'm open to the possibility that the logic is different in other animals. I just see no evidence that, at a deep level, it's true."

Stephen S. Hall is a science writer in New York who also teaches public communication to graduate students in science at New York University.

1. Garrison, J. L. et al. Science 338, 540-543 (2012)

2. Lorenz, K. So kam der Mensch auf den Hund (Man Meets Dog) (Deutscher Taschenbuch, 1950).

3. von Frisch, K. Du und das Leben (You and Life: A Biology for Everyman) (Ullstein Bucher, 1936)

4. Bargmann, C. I., Hung, M.-C. \& Weinberg, R. A. Nature 319, 226-230 (1986).

5. Ankeny, R. A. Nature Rev. Genet. 2, 474-479 (2001).

6. Bargmann, C. I. \& Horvitz, H. R. Neuron 7, 729-742 (1991).

7. Bargmann, C. I., Hartwieg, E. \& Horvitz, H. R. Cell 74, 515-527 (1993).

8. Sengupta, P., Chou, J. H. \& Bargmann, C. I. Cell 84, 899-909 (1996).

9. Gray, J. M., Hill, J. J. \& Bargmann, C. I. Proc. Natl Acad. Sci. 102, 3184-3191 (2005).

10.de Bono, M. \& Bargmann, C. I. Cell 94, 679-689 (1998)

11. Tinbergen, N. The Study of Instinct (Clarendon, 1951).

12.Bargmann, C. I. Bioessays 34, 458-465 (2012). 